\title{
USE OF BRICK DUST, FLY ASH AND CEMENT KILN DUST AS A REPLACEMENT OF FINE AGGREGATE IN SELF COMPACTING CONCRETE
}

\author{
ALI MOHD $^{1} \&$ ANKIT MAHAJAN ${ }^{2}$ \\ ${ }^{l}$ ME Scholar, Department of Civil Engineering Chandigarh University, Punjab, India \\ ${ }^{2}$ Assistant Professor, Department of Civil engineering, Chandigarh University, Mohali, Punjab, India
}

\begin{abstract}
Over the most recent five years, various SCC spans have been developed in Europe. In India, the utilization of SCC in expressway connect development is extremely restricted as of now. Nonetheless, India's precast solid industry is starting to apply the innovation to design concrete. SCC has high potential for more extensive basic applications in interstate scaffold development. The use of cement without vibration in roadway connect development isn't new. In the current Study, Attempt has been made to analyze the mechanical properties of self-compacting and ordinary solid examples and. The models utilized depended on 7days, 28-day and 56 days compressive, parting malleable and flexure quality and of regular and self-compacting concrete for five Fly debris, Brick residue and Cement furnace Dust proportions as a substitution to fine total.

KEYWORDS: Brick Dust, Fly Ash, Cement Kiln Dust \& Compacting Concrete
\end{abstract}

Received: Jun 08, 2020; Accepted: Jun 28, 2020; Published: Sep 03, 2020; Paper Id.: IJMPERDJUN20201031

\section{INTRODUCTION}

\section{SELF-COMPACTING CONCRETE}

Self-compacting concrete will be solid which, without the impact of extra compaction vitality, streams exclusively affected by the gravity, just as totally occupies the strengthening spaces and the formwork. Its basic properties are high flowability and great sedimentation strength. These properties can be accomplished by the utilization of expanded flour grain (flourcorn type), by balancing out added substances (stabilizer type) or by their mix in blend with exceptionally powerful stream specialists. Most of the individuals probably won't have the foggiest idea about a great deal about it or if nothing else don't care for it to an extreme yet, concrete is around us all over the place. In the event that you don't live alone in the focal point of a desert or an ocean, it would be ideal if you simply turn your head around and you will find this reality. There is no uncertainty that the solid is of uncommon significance in the structures and developments. Among the other structure and development materials (for example steel, block black-top, wood and so on.), it is still in the high level as indicated by its most noteworthy utilization contrasted with others around the world. As per the Cement Sustainability Initiative, the utilization of the solid is relied upon to be equivalent to 25 billion tons for each year which implies above 3.8 tons per individual every year on the planet. Solid innovation has made superb step in the previous decade. The development of determining a solid as indicated by its presentation prerequisites, marginally than the constituents and fixings has opened various open doors for makers of cement and clients to configuration cement to go with their specific necessities. Development of self-compacting concrete (SCC) is a needed achievement in the development business so as to conquer issues 
related with cast set up concrete.

\section{LITERATURE GAP}

- Various researchers have worked on use of these materials in SCC, however the research is limited to binomial materials only. The present research will emphasis on the use of tertiary combination of materials in SCC, the various mechanical properties as discussed above will be taken into consideration as well.

- In addition the proportioning of materials used in previous papers are giving a broader / tentative results, in present research the interval of proportion will give more precise results.

\section{OBJECTIVES}

- To relate the mechanical properties of self-compacting and normal concrete specimens.

- To Study the effect of various proportions of solo, binary and tertiary materials on the strength of SCC.

- To predict the optimal proportion of mix for best possible outcomes.

\section{MIXTURE PROPORTIONING}

Mix designations followed as per Table 3.11 are given below

Table 1:Mix Proportions of SCC

\begin{tabular}{|l|c|c|c|c|c|}
\hline \multicolumn{1}{|c|}{ Mix Design } & Control Mix & Mix 1 & Mix 2 & Mix3 & Mix 4 \\
\hline Cement (Kg/m3) & 475 & 475 & 475 & 475 & 475 \\
\hline Flyash $(\mathrm{kg})$ & 0 & 44 & 88 & 132 & 176 \\
\hline Brick Dust (kg) & 0 & 44 & 88 & 132 & 176 \\
\hline Cement Kiln Dust (kg) & 0 & 44 & 88 & 132 & 176 \\
\hline Coarse Aggregates $(\mathrm{kg})$ & 856 & 856 & 856 & 856 & 856 \\
\hline Fine Aggregates $(\mathrm{kg})$ & 891 & 759 & 627 & 495 & 363 \\
\hline Super Plasticizer $(\mathrm{kg} / \mathrm{m} 3)$ & 3.8 & 3.8 & 3.8 & 3.8 & 3.8 \\
\hline Water(Kg/m3) & 166 & 166 & 166 & 166 & 166 \\
\hline Water/Cement & 0.35 & 0.35 & 0.35 & 0.35 & 0.35 \\
\hline
\end{tabular}

- Control mix: $100.0 \%$ cement $100.0 \%$ fine aggregate

- Mix-1: $100.0 \%$ cement, $85 \%$ of fine aggregate content and 5.0\% fly ash, $5.0 \%$ Brick dust \& 5\% CKD

- Mix-2: $100.0 \%$ cement, $70 \%$ of fine aggregate content and $10.0 \%$ fly ash, $10.0 \%$ Brick dust \& $10 \%$ CKD

- Mix-3: $100.0 \%$ cement, $55 \%$ of fine aggregate content and $15.0 \%$ fly ash, $15.0 \%$ Brick dust \& $15 \%$ CKD

- Mix-4: $100.0 \%$ cement, $40 \%$ of fine aggregate content and $20.0 \%$ fly ash, $20.0 \%$ Brick dust \& $20 \%$ CKD 


\section{RESULTS AND CONCLUSIONS}

\section{Fresh Concrete Properties}

So as to examine the impact on new solid properties when Fly debris and Brick dust is included into the solid as fine total substitution, the SCC containing diverse extent of Fly debris and Brick dust were tried for Slump stream, V-channel, UBox, L-box. The consequences of new properties of all Self-compacting Fly debris and Brick dust cements are remembered for Table 4.1. The Table -2 shows the properties, for example, droop stream, V-pipe stream times, L-box, Ubox. As far as droop stream, all SCCs showed agreeable droop streams in the scope of 590-740 mm, which means that a decent deformability.

Table 2: Fresh Concrete Properties

\begin{tabular}{|l|c|c|c|c|}
\hline \multicolumn{1}{|c|}{ Mixture ID } & Slump (mm) & $\begin{array}{c}\text { V-Funnel } \\
\text { (Seconds) }\end{array}$ & L-Box (H2/H1) & U-Box (H1-H2) \\
\hline Normal mix & 687 & 9 & 0.9 & 30 \\
\hline Mix 1 & 590 & 13 & - & - \\
\hline Mix 2 & 704 & 11 & - & 35 \\
\hline Mix 3 & 740 & 12 & 0.9 & 35 \\
\hline Mix 4 & 720 & 9 & 1.0 & - \\
\hline
\end{tabular}

\section{Compressive Strength}

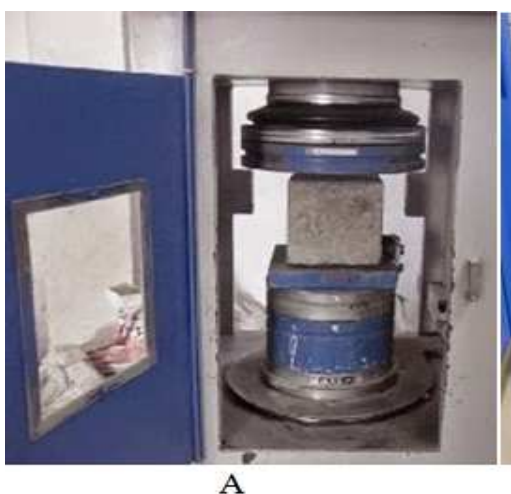

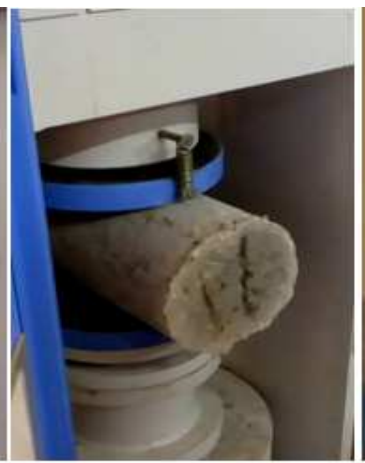

B

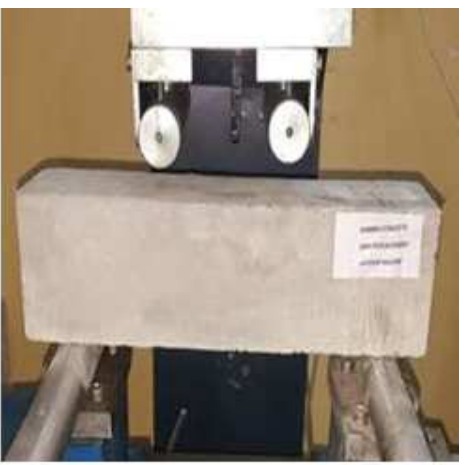

C

Figure 1: A, B \& C are Photographs for Compressive, Tensile and Flexural Strength Testing.

Table 3: Compressive Strength of SCC Mix

\begin{tabular}{|c|c|c|c|c|c|c|}
\hline \multirow{2}{*}{ MIX } & \multicolumn{3}{|c|}{ Compressive Strength $\left(\mathrm{N} / \mathrm{mm}^{2}\right)$} & \multicolumn{3}{|c|}{ Average Compressive Strength $\left(\mathrm{N} / \mathrm{mm}^{2}\right)$} \\
\hline & 7 days & 28 days & 56 days & 7 days & 28 days & 56 days \\
\hline \multirow{3}{*}{ Normal mix } & 38.96 & 51.19 & 67.34 & \multirow{3}{*}{38.36} & \multirow{3}{*}{51.99} & \multirow{3}{*}{66.35} \\
\hline & 37.78 & 52.14 & 65.23 & & & \\
\hline & 38.34 & 52.65 & 66.49 & & & \\
\hline \multirow{3}{*}{ Mix 1} & 39.98 & 53.98 & 68.83 & \multirow{3}{*}{39.92} & \multirow{3}{*}{54.29} & \multirow{3}{*}{69.01} \\
\hline & 39.67 & 54.12 & 69.89 & & & \\
\hline & 40.12 & 54.78 & 68.32 & & & \\
\hline \multirow{3}{*}{ Mix 2} & 41.21 & 55.65 & 69.89 & \multirow{3}{*}{41.54} & \multirow{3}{*}{55.44} & \multirow{3}{*}{69.41} \\
\hline & 41.20 & 54.89 & 69.02 & & & \\
\hline & 42.23 & 55.78 & 69.34 & & & \\
\hline \multirow{3}{*}{ Mix 3} & 43.12 & 56.78 & 71.67 & \multirow{3}{*}{43.43} & \multirow{3}{*}{57.96} & \multirow{3}{*}{71.29} \\
\hline & 43.85 & 58.67 & 70.97 & & & \\
\hline & 43.34 & 58.45 & 71.23 & & & \\
\hline \multirow{3}{*}{ Mix 4} & 44.89 & 61.78 & 73.20 & \multirow{3}{*}{44.63} & \multirow{3}{*}{62.70} & \multirow{3}{*}{74.15} \\
\hline & 44.45 & 62.89 & 74.02 & & & \\
\hline & 44.56 & 63.45 & 75.23 & & & \\
\hline
\end{tabular}




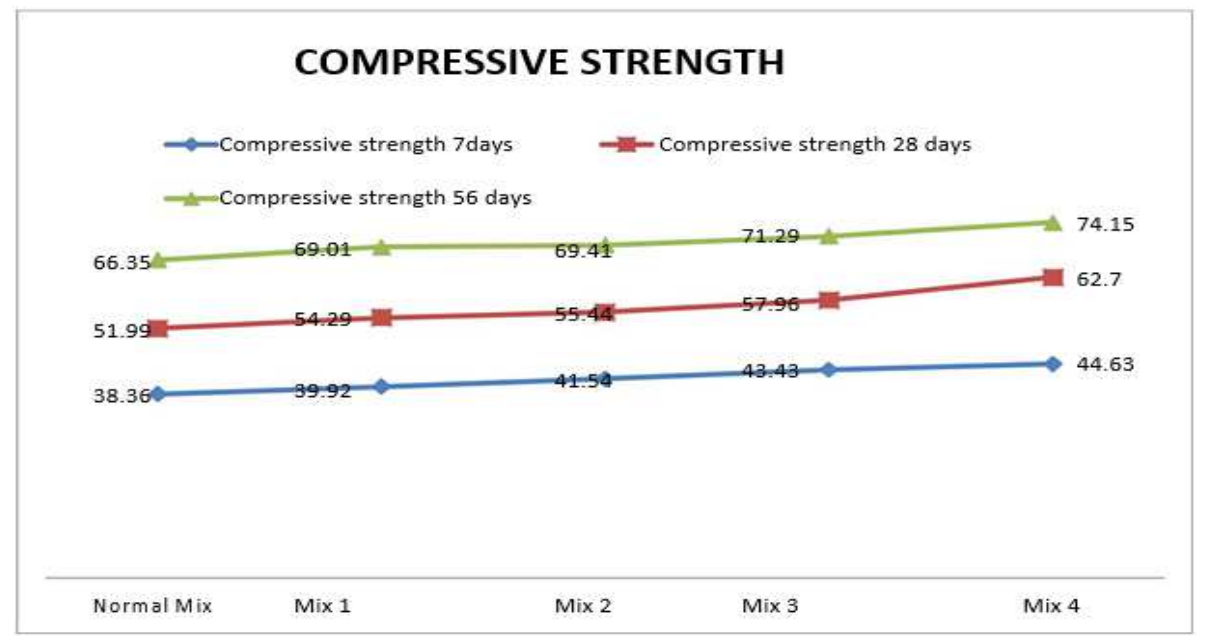

Figure 2: Compressive Strength Graph Chart.

Splitting Tensile Strength

Table 4: Tensile Strength Properties

\begin{tabular}{|c|c|c|c|c|c|c|}
\hline \multirow{2}{*}{ MIX } & \multicolumn{2}{|c|}{ Tensile Strength $\left(\mathrm{N} / \mathrm{mm}^{2}\right)$} & \multicolumn{4}{|c|}{ Average Tensile strength $\left(\mathrm{N} / \mathrm{mm}^{2}\right)$} \\
\hline & 7 days & 28 days & 56 days & 7 days & 28 days & 56 days \\
\hline \multirow{3}{*}{ Normal mix } & 2.74 & 3.45 & 4.21 & \multirow{3}{*}{2.72} & \multirow{3}{*}{3.45} & \multirow{3}{*}{4.19} \\
\hline & 2.45 & 3.67 & 4.15 & & & \\
\hline & 2.98 & 3.23 & 4.23 & & & \\
\hline \multirow{3}{*}{ Mix 1} & 2.88 & 3.67 & 4.44 & \multirow{3}{*}{3.00} & \multirow{3}{*}{3.77} & \multirow{3}{*}{4.38} \\
\hline & 3.10 & 3.76 & 4.49 & & & \\
\hline & 3.02 & 3.88 & 4.23 & & & \\
\hline \multirow{3}{*}{ Mix 2} & 3.31 & 3.89 & 4.56 & \multirow{3}{*}{3.22} & \multirow{3}{*}{3.85} & \multirow{3}{*}{4.68} \\
\hline & 3.21 & 3.69 & 4.78 & & & \\
\hline & 3.15 & 3.97 & 4.71 & & & \\
\hline \multirow{3}{*}{ Mix 3} & 3.56 & 4.11 & 4.89 & \multirow{3}{*}{3.59} & \multirow{3}{*}{4.25} & \multirow{3}{*}{4.95} \\
\hline & 3.78 & 4.21 & 4.95 & & & \\
\hline & 3.43 & 4.45 & 5.01 & & & \\
\hline \multirow{3}{*}{ Mix 4} & 3.87 & 4.62 & 5.23 & \multirow{3}{*}{3.92} & \multirow{3}{*}{4.61} & \multirow{3}{*}{5.37} \\
\hline & 3.92 & 4.78 & 5.34 & & & \\
\hline & 3.97 & 4.45 & 5.55 & & & \\
\hline
\end{tabular}

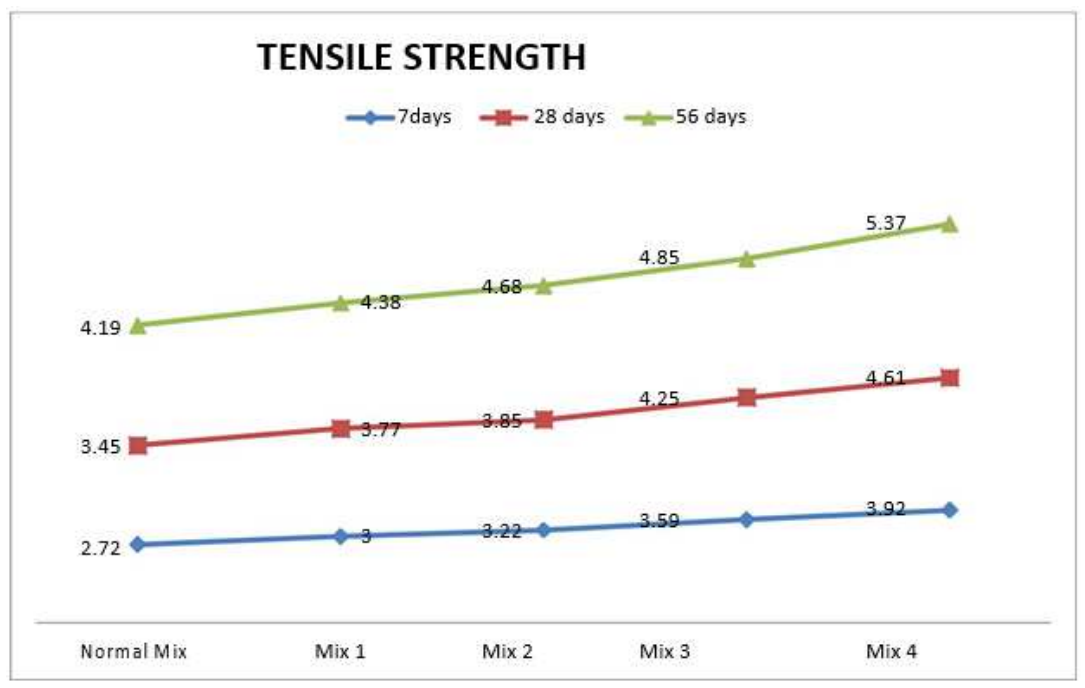

Figure 3: Tensile Strength Graph Chart. 


\section{Flexure Strength}

The flexural quality of the solid blend was estimated at 7 days 28 days $\& 56$ days by utilizing general testing machine on standard light emissions $100 \mathrm{mmx} 100 \mathrm{mmx} 500 \mathrm{~mm}$ ). The flexural quality was found to increment for all blends at the entire days in contrast with control blend.

Table 5: Flexure Strength

\begin{tabular}{|c|c|c|c|c|c|c|}
\hline \multirow{2}{*}{ MIX } & \multicolumn{3}{|c|}{ Flexure Strength $\left(\mathrm{N} / \mathrm{mm}^{2}\right)$} & \multicolumn{3}{|c|}{ Flexure Strength $\left(\mathrm{N} / \mathrm{mm}^{2}\right)$} \\
\hline & 7 days & 28 days & 56 days & 7 days & 28 days & 56 days \\
\hline \multirow{3}{*}{ Normal mix } & 4.23 & 5.65 & 6.34 & \multirow{3}{*}{4.33} & \multirow{3}{*}{5.51} & \multirow{3}{*}{6.35} \\
\hline & 4.41 & 5.54 & 6.45 & & & \\
\hline & 4.36 & 5.34 & 6.28 & & & \\
\hline \multirow{3}{*}{ Mix 1} & 4.45 & 5.67 & 6.67 & \multirow{3}{*}{4.50} & \multirow{3}{*}{5.71} & \multirow{3}{*}{6.54} \\
\hline & 4.49 & 5.73 & 6.44 & & & \\
\hline & 4.56 & 5.75 & 6.53 & & & \\
\hline \multirow{3}{*}{ Mix 2} & 4.76 & 5.86 & 6.65 & \multirow{3}{*}{4.78} & \multirow{3}{*}{5.85} & \multirow{3}{*}{6.71} \\
\hline & 4.81 & 5.89 & 6.78 & & & \\
\hline & 4.78 & 5.81 & 6.70 & & & \\
\hline \multirow{3}{*}{ Mix 3} & 4.89 & 5.98 & 6.91 & \multirow{3}{*}{4.89} & \multirow{3}{*}{5.92} & \multirow{3}{*}{6.85} \\
\hline & 4.83 & 5.87 & 6.86 & & & \\
\hline & 4.96 & 5.92 & 6.79 & & & \\
\hline \multirow{3}{*}{ Mix 4} & 5.34 & 6.08 & 7.01 & \multirow{3}{*}{5.62} & \multirow{3}{*}{6.05} & \multirow{3}{*}{7.15} \\
\hline & 5.55 & 6.12 & 7.08 & & & \\
\hline & 5.98 & 6.97 & 7.36 & & & \\
\hline
\end{tabular}

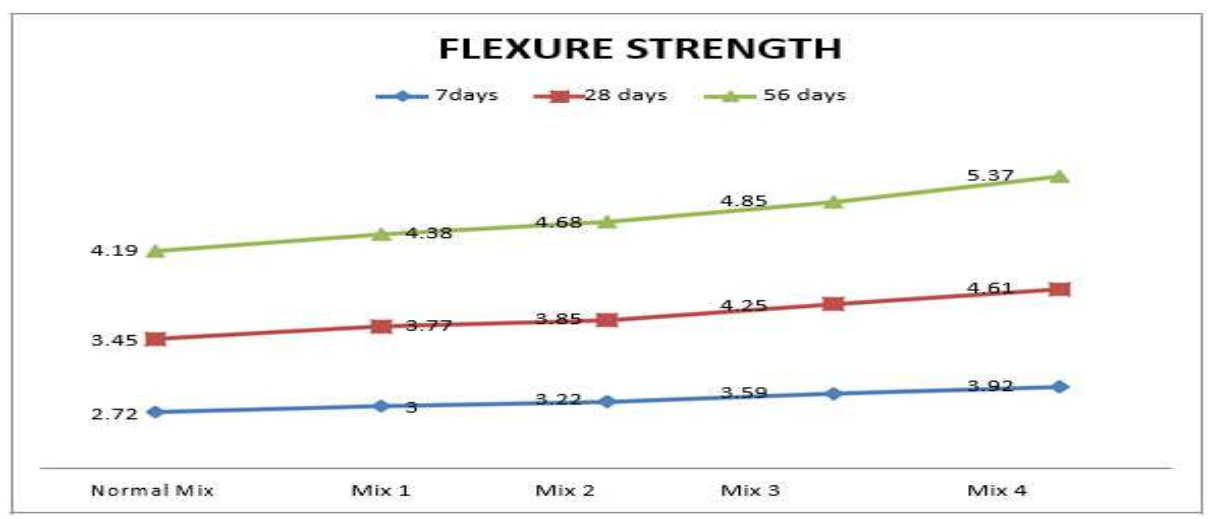

Figure 4: Flexure Strength Line Graph.

\section{CONCLUSIONS}

- The properties, for example, droop stream, V-pipe stream times, L-box, U-box. As far as droop stream, all SCCs showed acceptable droop streams in the scope of 590-740 mm, which means that a decent deformability.

- The compressive quality expanded with an Increase in the level of the Fly debris and Brick dust. An expansion of about $37 \%$ quality at 7 days, $15 \%$ quality at 28 days and $8 \%$ at 56 days was seen with the increment of Fly debris and Brick dust content from 5\% (SCC MIX1) to 20\% (SCC MIX4).

- It was seen that the \%age increment in compressive quality was progressively overwhelming at early ages.

- The quality was expanded at later ages likewise yet not all that rapidly in light of the fact that the pozzolanic response of the fly debris is all the more quick at early ages and the block dust goes about as a filler additionally alongside pozzolanic action against the fine total which goes about as a filler item in particular. 
- The split rigidities of SCC following 7 days are practically identical to those gotten following 28 days for NC. This was conceivable as a result of the utilization of Fly debris and Brick dust as fine total substitution, which normally will in general increment the early quality of cement.

- The flexural quality was found to increment for all blends at the entire days in contrast with control blend.

\section{REFERENCES}

1. Dr. R. Sri Ravindrarajah, D. Siladyi and B. Adamopoulos, "Development of High-Strength Self-Compacting Concrete with reduced Segregation Potential” 1 Vol., 1048 pp., ISBN: 2-912143-42-X.

2. Felekoglu, B., Turkel, S., Baradan, B, "Effect of w/c ratio on the fresh and hardened properties of SCC" Building and Environment Research vol: 35, pp.373-379

3. Kazumasa OZAWA, Anura S.M.Nanayakkara and Koichi Maekawa : Application of Multi-Phase Model to the Pipe Flow of Fresh Concrete Proceedings of JSCE,No.466/V-19,pp.121-131,1993

4. Khayat, K.H., Vachon, M., Lanctot, M.C. (1997). Use of Blended Silica Fume Cement in Commercial Concrete Mixtures, ACI Materials Journal, pp.183-192

5. N. Bouzoubaa and M. Lachemi, "Self-compacting concrete incorporating high volumes of class F fly ash Preliminary results" Cement and Concrete Research, 31, 2001, pp 413-420.

6. Nan Su, Kung-Chung Hsu and His-Wen Chai, "A simple mix design method for self-compacting concrete" Cement and Concrete Research, 31, 2001, pp 1799-1807

7. Okamura, H. (1997). Self-Compacting High-Performance Concrete, Concrete International, pp.50-54.

8. Paratibha Aggarwal, Rafat Siddique, Yogesh Aggarwal and Surinder M Gupta, "Self-Compacting Concrete - Procedure for Mix Design" Leonardo Electronic Journal of Practices and Technologies, Issue 12, 2008, pp 15-24

9. S. Girish, R.V. Ranganath and JagadishVengala, "Influence of powder and paste on flow properties of SCC" Construction and Building Materials, 24, 2010, pp 2481-2488.

10. Subramanian .S and Chattopadhyay (2002),"Experiments for Mix Proportioning of Self Compacting Concrete", Indian Concrete Journal, January, Vol., PP 13-20

11. Inegbenebor, Adedayo I., et al. "Consequences of the Activities of a Nigerian Cement Industry on the Environment." International Journal of Applied and Natural Sciences (IJANS) 7.4 (2018): 67-74.

12. Aulakh, Deepinder Singh, Sarvesh Kumar, and Ramandeep Singh Cheema. "Unconfined Compressive Strength of Cement Stabilized Pond Ash." International Journal of Civil, Structural, Environmental and Infrastructure Engineering Research and Development (IJCSEIERD) 8.3 (2018): 7-14

13. Sharma, Nikita, and B. Jena. "Behaviour of Flyash Brick Masonry Columns." International Journal of Civil Engineering (IJCE) 6.1 (2017): 9-14.

14. Cheema, R. M., Deepinder Singh Aulakh, and Sarvesh Kumar. "Durability of cement stabilized pond ash." International Journal of Civil, Structural, Environmental and Infrastructure Engineering Research and Development (IJCSEIERD) 6.2 (2016): 17-28. 